\title{
Psychological Impact of Probiotics and Fermented Foods on Mental Health of Human in Integrated Healthy Lifestyle
}

\author{
N.F. Nasr* \\ Department of Microbiology, Faculty of Agriculture, Cairo University, Giza, Egypt, 12613 \\ *Corresponding author
}

\section{A B S T R A C T}

\section{Keywords \\ Mental health, Gut microbiota, Probiotics, Psychobiotics, \\ Therapeutic nutrition, Human lifestyle, \\ Fermented foods \\ Article Info \\ Accepted: \\ 15 July 2018 \\ Available Online: \\ 10 August 2018}

Effect of probiotic gut microbiota on host health is very interesting for scientists as an example for active interactions among different living organisms. This article answers basic questions about this interaction, its effects on human mental health and its application in healthy and therapeutic nutrition of host. Mechanisms of gut microbiota affecting human mental health and limitations of probiotics in host gut were discussed. Probiotics application in healthy nutrition is only one factor in integrated healthy lifestyle for good physical and mental health of human.

\section{Introduction}

Attention has been almost concerned with the negative effects that microorganisms play in food, there is however a huge diversity of foods where microbial activity is an essential feature of their production in addition to benefits of these microorganisms for host health. Therefore, fermented foods and probiotic products can be used to enhance human general health and may be used to support recovery of some diseases under concept of therapeutic nutrition.

Probiotic gut microbiota have multi beneficial effects for host; improvement digestion and intestinal health, inhibition of pathogens in intestinal tract, enhancement and induction of immune system response, anti-inflammatory activity, production of vitamins and cofactors, reduction of serum cholesterol, anti-oxidative activity, reduction of blood pressure, prevention of cancer and tumors, improvement of lactose metabolism in lactose intolerant persons and protective role against allergy (Santosa et al., 2006; FigueroaGonzález et al., 2011; Shinde, 2011; Nagpal et al., 2012; Kechagia et al., 2013; Turroni et al., 2014; Amara and Shibl, 2015).

Availability of safe food - per se - can enhance human psychological health. Are some food types having positive effect on human mental health? Historically, fermented 
foods provided good physical and physiological health of some peoples. It is known that, psychological health relates to physiological and physical health with bidirectional effect; one of both can affect the other. But what is the true value of fact that, probiotic fermented foods can enhance human behavior and mental health. Nowadays, this concept is used for production of specific fermented foods and probiotic supplements under terminology of Psychobiotics.

\section{Effect of probiotic bacteria on host mental health}

Several experimental studies reported that, supplementation with probiotic bacteria in food can influence nervous system function and mental health and provide beneficial neurochemicals and positive behavioral effects of animal or human host (Neufeld et al., 2011; Desbonnet et al., 2014; Nishihira et al., 2014; Savignac et al., 2014; Hilimire et al., 2015; Steenbergen et al., 2015; Akkasheh et al., 2016; Cowan et al., 2016). Furthermore, effect of probiotic gut microbiota on brain activity of healthy humans was demonstrated using functional magnetic resonance imaging (fMRI) (Tillisch et al., 2013).

In preclinical study with rats and clinical study with volunteers, results deduced that daily consumption of probiotic strains (Lactobacillus helveticus and Bifidobacterium longum) for two weeks can significantly reduced anxiety-like behavior in rats and alleviated psychological distress in volunteers.

Which was evidence of gut microbiota role on central nervous system functions and suggests that oral intake of probiotics may have beneficial consequences on mood and psychological distress of host (Messaoudi et al., 2011).
Cross-sectional approach was applied with 710 young adults using completed self-report measures to determine interaction between consumption of natural fermented foods and neuroticism for predicting social anxiety symptoms. Results reported that higher frequency consumption of natural fermented foods that may contain probiotics was associated with fewer symptoms of social anxiety, which indicate that fermented foods have a protective effect against social anxiety symptoms (Hilimire et al., 2015).

Forty patients in randomized, double-blind clinical trial with major depressive disorder (whose age between 20 and 55 years) were divided to two groups; one group received probiotic capsules contained Lactobacillus acidophilus $\left(2 \times 10^{9} \mathrm{CFU} / \mathrm{g}\right)$, Lactobacillus casei $\left(2 \times 10^{9} \mathrm{CFU} / \mathrm{g}\right)$, and Bifidobacterium bifidum $\left(2 \times 10^{9} \mathrm{CFU} / \mathrm{g}\right)$ for 8 weeks, the other group received placebo capsules. Results reported that, probiotic supplement group has significantly decreased Beck Depression Inventory compared with the placebo group (Akkasheh et al., 2016).

Seventy-five workers in a randomized, double-blind, placebo-controlled trial received yogurt and capsules for 6 weeks in 3 groups. Results indicated that consumption of probiotic yogurt (contained two strains; Lactobacillus acidophilus and Bifidobacterium lactis) or a multispecies probiotic capsule (contained seven probiotic bacteria spices Lactobacillus case $i, L$. acidophilus, L. rhamnosus, L. bulgaricus, Bifidobacterium breve, $B$. longum, Streptococcus thermophilus) had significant beneficial effects on mental health parameters of workers (Mohammadi et al., 2016).

Contrarily, in a double-blind, randomized, placebo controlled trial for 8 weeks; probiotic preparation (containing Lactobacillus helveticus and Bifidobacterium longum) failed 
to reduce depression symptoms of seventynine participants, where the result indicated that no significant difference was found between the probiotic and placebo groups on any psychological outcome measures. Authors mentioned that this result may be due to the severity, chronicity or treatment resistance of the sample and acute symptoms of low mood of the participants, also using probiotics in future as an adjuvant treatment may be more effective (Romijn et al., 2017).

Potential psychobiotic bacterial strain (Lactobacillus rhamnosus (JB-1)) could not improve stress-related behaviors, inflammatory response, cognitive performance of 29 healthy male volunteers after 8 weeks in randomized, placebocontrolled trial, where there is no significant effect of probiotic treatment over placebo (Kelly et al., 2017).

\section{Mechanisms of gut microbiota affecting host mental health}

Multiple mechanisms are considered; probiotic bacteria able to influence the immune-related pathways (Desbonnet et al., 2008), Probiotic gut microbiota can reduce pro-inflammatory cytokines (Lin et al., 2008) and oxidative stress (Kullisaar et al., 2003; Lopresti et al., 2014) in host, which are associated with depression and mood disorders (Dowlati et al., 2010; Stefanescu and Ciobica, 2012). Gut has a complex nervous system interfaces directly with the brain and allows bidirectional flow of information between gut microbiota and brain. There are multiple pathways of communication between gut microbiota and central nervous system including vagus nerve, immune and hypothalamic pituitary adrenal axis, which can modulate cognition, emotion and behavior of host as the microbiota-gutbrain axis (Foster and Neufeld, 2013; Tillisch, 2014).
Immunological, neurophysiological and microbiological systems in human body can interact to control and affect health and diseases such as mental health or emotional and mood disorders of host using neuroactive substances (neurotransmitters such as Serotonin, Dopamine, Acetylcholine, Norepinephrine, gamma-aminobutyric acid) which can be produced in the same identical structure by gut microbiota or human body cells itself (Lyte, 2004 \& 2010; Komatsuzaki et al., 2008; Reiff and Kelly, 2010; Jiang et al., 2015), as a communication between bacterial cells in gut and human body cells.

The interaction acts in different directions, probiotic gut microbiota have the ability to both synthesize and respond to neuroactive compounds, which means that growth and colonization of probiotic gut microbiota in gastrointestinal tract can be affected by physical, physiological and mental health of host, it is a life interaction communication among all biotic and abiotic components of life ecosystems.

There is a symbiotic interaction between gut microbiota and host body. Gut microbiota can affect physical, physiological, immune and mental health of host. So, some scientists consider gut microbiota as an additional organ in our body.

Ability of probiotic gut microbiota to produce the neuroactive substances depends on presence of some substances in gut as substrates, which may be found in the probiotic food product or other foods.

For example, probiotic bacteria need glutamate as substrate and pyridoxal phosphate as enzyme co-factor for production of gamma-aminobutyric acid (Komatsuzaki et al., 2008). Also, probiotic microbiota utilize tryptophan as a precursor for production of serotonin (O’Mahony et al., 2015). 


\section{Limitations of probiotics in host gut}

There are things that kill or inhibit and reduce count and colonization of our good friend bacteria (probiotics) in host gut; antibiotics therapy, drinking treated water with chlorine or fluoride, high-sugar and fat-diets consumption, exposure to toxic pollutants and social and psychological stresses (Bailey et al., 2011; Dethlefsen and Relman, 2011; Bergin and Witzmann, 2013; Pérez-Cobas et al., 2013; Shehata et al., 2013; Liu et al., 2014; Taggart and Bergstrom, 2014; Jiang et al., 2015; Murphy et al., 2015; Jena et al., 2016). Therefore, fermented foods or probiotic supplemented products have to be eaten daily to support host health.

At the other side, eating of fresh and raw foods such as onion, garlic, leek, wheat, barley, oat, banana, apple, asparagus, Jicama, Jerusalem artichokes and chicory stimulates growth and activity of probiotic microbiota in host gut, because these foods contain prebiotic substances (such as; oligosaccharide fibers like inulin, fructooligosaccharides (fructans), galactooligosaccharides (galactans)) that can only be metabolized by the probiotic microbiota and non-digestible by host.

Sufficient amount of prebiotic foods must be eaten to generate a prebiotic effect, but not too lot to induce unfavorable or adverse effects such as non-selective utilization and excessive gas formation (Kleessen et al., 2007; Roberfroid, 2007; Muir et al., 2007; Macfarlane et al., 2008; Slavin, 2013; Zhang et al.,2013; Arena et al., 2014; Kumar et al., 2015; Valeur et al., 2016; Gibson et al., 2017).

Plant polyphenols, polyunsaturated fatty acids and conjugated linoleic acid may be considered as prebiotic substances (Gibson et al., 2017).

\section{Integrated healthy lifestyle}

In a simple way, you can try the following for good general, physical, physiological and mental health of human as integrated healthy lifestyle:

Healthy nutrition depends on variation and moderation of human foods, eat your food with your all senses. Healthy habits and behaviors; anything wants to exit (something from your body, idea from your mind, word from your tongue, reaction from your sentiment, emotion from your psyche) get it out (without annoyance for others), do not keep it in.

Healthy life can be achieved by direct, active, positive and psychical interactions by all senses of human with all visible and invisible components of nature as a full ecosystem; biotic factors (humans, animals, plants, microorganisms) and abiotic factors (sun light, fresh air, fresh and marine water, land terrain, soil, elements).

Probiotic fermented foods and probiotic supplements products can enhance human behavior and mental health, it is an effective but not invasive treatment. It can be used as an important adjuvant factor for healthy nutrition or treatment of mental health disorders or other diseases. Probiotics application in healthy nutrition is only one factor in integrated healthy lifestyle for good physical and mental health of human.

\section{Acknowledgment}

The author would like to express thanks and sincere gratitude to Dr. Fatma-Elzahraa Abdelbasit, Department of Mental Health, Faculty of Education, Helwan University, for invaluable discussions about psychological concepts and terminology of Mental Health science. 


\section{References}

Akkasheh G, Poor Z K, Ebrahimi M T, Jafari $\mathrm{P}$, Akbari $\mathrm{H}$, Taghizadeh $\mathrm{M}$, Memarzadeh M R, Asemi $\mathrm{Z}$ and Esmaillzadeh A. 2016. Clinical and metabolic response to probiotic administration in patients with major depressive disorder: A randomized, double-blind, placebo-controlled trial. Nutrition 32: 315 - 320.

Amara AA and Shibl A. 2015. Role of Probiotics in health improvement, infection control and disease treatment and management. Saudi Pharmaceutical Journal 23: 107 - 114.

Arena MP, Caggianiello G, Fiocco D, Russo P, Torelli M, Spano G and Capozzi V. 2014. Barley $\beta$-Glucans-Containing Food Enhances Probiotic Performances of Beneficial Bacteria. Int. J. Mol. Sci. 15: 3025 - 3039 .

Bailey MT, Dowd SE, Galley JD, Hufnagle AR, Allen RG and Lyte M. 2011. Exposure to a social stressor alters the structure of the intestinal microbiota: implications for stressor-induced immunomodulation. Brain, Behavior and Immunity 25: 397- 407.

Bergin IL and Witzmann FA. 2013. Nanoparticle toxicity by the gastrointestinal route: evidence and knowledge gaps. International Journal of Biomedical Nanoscience and Nanotechnology 3: DOI: 10.1504/IJBNN.2013.054515.

Cowan CSM, Callaghan BL and Richardson R. 2016. The effects of a probiotic formulation (Lactobacillus rhamnosus and $L$. helveticus) on developmental trajectories of emotional learning in stressed infant rats. Translational Psychiatry 6: e823; doi:10.1038/ tp.2016.94.

Desbonnet L, Clarke G, Shanahan F, Dinan TG and Cryan JF. 2014. Microbiota is essential for social development in the mouse. Mol Psychiatry 19: 146 - 148.

Desbonnet L, Garrett L, Clarke G, Bienenstock J and Dinan TG. 2008. The probiotic Bifidobacteria infantis: an assessment of potential antidepressant properties in the rat. J Psychiatr. Res. 43: $164-74$

Dethlefsen L and Relman D A. 2011. Incomplete recovery and individualized responses of the human distal gut microbiota to repeated antibiotic perturbation. Proc. Natl Acad. Sci. USA 108: 4554 - 4561.

Dowlati Y, Herrmann N, Swardfager W, Liu H, Sham L, Reim EK and Lanctôt KL. 2010. A meta-analysis of cytokines in major depression. Biological Psychiatry 67: $446-457$

Figueroa-González I, Cruz-Guerrero A and Quijano G. 2011. The Benefits of Probiotics on Human Health. J Microbial Biochem Technol S1:003. doi: 10.4172/1948-5948.S1-003

Foster JA and Neufeld KAM. 2013. Gutbrain axis: how the microbiome influences anxiety and depression. Trends Neurosci. 36: $305-312$.

Gibson GR, Hutkins R, Sanders ME, Prescott SL, Reimer RA, Salminen SJ, Scott K, Catherine Stanton C, Swanson KS, Cani PD, Verbeke K and Reid G. 2017. Expert consensus document: The International Scientific Association for Probiotics and Prebiotics (ISAPP) consensus statement on the definition and scope of prebiotics. Nature Reviews Gastroenterology \& Hepatology 14: 491 -502 .

Hilimire MR, DeVylder JE and Forestell CA. 2015. Fermented foods, neuroticism, and social anxiety: An interaction model. Psychiatry Research 228: 203 208.

Jena PK, Prajapati B, Mishra PK and Seshadri S. 2016. Influence of Gut Microbiota on 
Inflammation and Pathogenesis of Sugar Rich Diet Induced Diabetes. Immunome Research 12:109. doi:10.4172/1745-7580.10000109.

Jiang H, Ling Z, Zhang Y, Mao H, Ma Z, Yin Y, Wang W, Tang W, Tan Z, Shi J, Li L and Ruan B. 2015. Altered fecal microbiota composition in patients with major depressive disorder. Brain Behav Immun 48: 186 - 194.

Kechagia M, Basoulis D, Konstantopoulou S, Dimitriadi D, Gyftopoulou K, Skarmoutsou N and Fakiri EM. 2013. Health Benefits of Probiotics: A Review. ISRN Nutrition 2013: 1-7.

Kelly JR, Allen AP, Temko A, Hutch W, Kennedy PJ, Farid N, Murphy E, Boylan G, Bienenstock J, Cryan JF, Clarke G and Dinan TG. 2017. Lost in Translation? The potential psychobiotic Lactobacillus rhamnosus (JB-1) fails to modulate stress or cognitive performance in healthy male subjects. Brain, Behavior and Immunity 61: 50 59.

Kleessen B, Schwarz S, Boehm A, Fuhrmann $\mathrm{H}$, Richter A, Henle T and Krueger M. 2007. Jerusalem artichoke and chicory inulin in bakery products affect faecal microbiota of healthy volunteers. Br. J. Nutr. 98: 540 - 549.

Komatsuzaki N, Nakamura T, Kimura T and Shima J. 2008. Characterization of glutamate decarboxylase from a high gamma-aminobutyric acid (GABA)producer, Lactobacillus paracasei. Biosci Biotechnol Biochem 72: 278 285.

Kullisaar T, Songisepp E, Mikelsaar M, Zilmer K, Vihalemm $\mathrm{T}$ and Zilmer $\mathrm{M}$. 2003. Antioxidative probiotic fermented goats' milk decreases oxidative stressmediated atherogenicity in human subjects. British Journal of Nutrition 90: $449-456$.
Kumar VP, Prashanth KV and Venkatesh YP. 2015. Structural analyses and immunomodulatory properties of fructo-oligosaccharides from onion (Allium cepa). Carbohydr. Polym. 117:115-122.

Lin YP, Thibodeaux CH, Pena JA, Ferry GD and Versalovic J. 2008. Probiotic Lactobacillus reuteri suppress proinflammatory cytokines via c-Jun. Inflammatory Bowel Diseases 14: 1068 $-1083$.

Liu Y, Li Y, Liu K and Shen J. 2014. Exposing to Cadmium Stress Cause Profound Toxic Effect on Microbiota of the Mice Intestinal Tract. PLoS ONE 9: e85323.

doi:10.1371/journal.pone.0085323.

Lopresti AL, Maker GL, Hood SD and Drummond PD. 2014. A review of peripheral biomarkers in major depression: the potential of inflammatory and oxidative stress biomarkers. Prog. Neuropsychopharmacol. Biol. Psychiatry 48: $102-111$.

Lyte M. 2004. Microbial endocrinology and infectious disease in the 21st century. Trends Microbiol 12: $14-20$.

Lyte M. 2010. The microbial organ in the gut as a driver of homeostasis and disease. Med Hypotheses 74: 634 - 638.

Macfarlane GT, Steed H and Macfarlane S. 2008. Bacterial metabolism and healthrelated effects of galactooligosaccharides and other prebiotics. J. Appl. Microbiol. 104: 305 - 344.

Messaoudi M, Lalonde R, Violle N, Javelot H, Desor D, Nejdi A, Bisson JF, Rougeot C, Pichelin M, Cazaubiel M and Cazaubiel JM. 2011. Assessment of psychotropic-like properties of a probiotic formulation (Lactobacillus helveticus R0052 and Bifidobacterium longum R0175) in rats and human 
subjects. British Journal of Nutrition 105: 755 - 764 .

Mohammadi AA, Jazayeri S, KhosraviDarani K, Solati Z, Mohammadpour N, Asemi Z, Adab Z, Djalali M, TehraniDoost M, Hosseini M and Eghtesadi S. 2016. The effects of probiotics on mental health and hypothalamicpituitary-adrenal axis: A randomized, double-blind, placebo-controlled trial in petrochemical workers. Nutritional Neuroscience 19: 387 - 395.

Muir JG, Shepherd SJ, Rosella O, Rose R, Jacqueline S. Barrett JS and Gibson PR. 2007. Fructan and Free Fructose Content of Common Australian Vegetables and Fruit. J. Agric. Food Chem. 55: 6619 - 6627.

Murphy EA, Velazquez KT and Herbert KM. 2015. Influence of High-Fat-Diet on Gut Microbiota: A Driving Force for Chronic Disease Risk. Curr Opin Clin Nutr Metab Care 18: 515 - 520.

Nagpal R, Kumar A, Kumar M, Behare PV, Jain S and Yadav H. 2012. Probiotics, their health benefits and applications for developing healthier foods: a review. FEMS Microbiology Letters 334: 1 15.

Neufeld KM, Kang N, Bienenstock $\mathbf{J}$ and Foster JA. 2011. Reduced anxiety-like behavior and central neurochemical change in germ-free mice. Neurogastroenterol Motil 23: 255-264.

Nishihira J, Kagami-Katsuyama H, Tanaka A, Nishimura M, Kobayashi $\mathrm{T}$ and Kawasaki Y. 2014. Elevation of natural killer cell activity and alleviation of mental stress by the consumption of yogurt containing Lactobacillus gasseri SBT2055 and Bifidobacterium longum SBT2928 in a double-blind, placebo controlled clinical trial. J Funct Foods 11: $261-268$.

O’Mahony SM, Clarke G, Borre YE, DinanTG and Cryan JF. 2015.
Serotonin, tryptophan metabolism and the brain-gut-microbiome axis. Behav Brain Res 277: 32-48.

Pérez-Cobas AE, Gosalbes MJ, Friedrichs A, Knecht H, Artacho A, Eismann K, Otto W, Rojo D, Bargiela R, von Bergen M, Neulinger SC, Däumer C, Heinsen FA, Latorre A, Barbas C, Seifert J, dos Santos VM, Ott SJ, Ferrer M and Moya A. 2013. Gut microbiota disturbance during antibiotic therapy: a multi-omic approach.Gut 62: 1591 - 1601.

Reiff C and Kelly D. 2010. Inflammatory bowel disease, gut bacteria and probiotic therapy. Int $\mathrm{J}$ Med Microbiol 300: $25-33$.

Roberfroid M. 2007. Prebiotics: The Concept Revisited. The Journal of Nutrition 137: 830S - 837S.

Romijn AR, Rucklidge JJ, Kuijer RG and Frampton C. 2017. A double-blind, randomized, placebo controlled trial of Lactobacillus helveticus and Bifidobacterium longum for the symptoms of depression. Australian \& New Zealand Journal of Psychiatry 51: $810-821$.

Santosa S, Farnworth E and Jones PJH. 2006. Probiotics and Their Potential Health Claims. Nutrition Reviews 64: 265 274.

Savignac HM, Kiely B, Dinan TG and Cryan JF. 2014. Bifidobacteria exert strainspecific effects on stress-related behavior and physiology in BALB/c mice. Neurogastroenterol Motil 26: 1615 - 1627 .

Shehata AA, Schrödl W, Aldin AA, Hafez HM and Krüger M. 2013. The Effect of Glyphosate on Potential Pathogens and Beneficial Members of Poultry Microbiota In Vitro. Current Microbiology. 66: $350-358$.

Shinde PB. 2011. Probiotic: an overview for selection and evaluation. Int. J. Pharm. Pharm. Sci. 4: 14 - 21. 
Slavin J. 2013. Fiber and prebiotics: mechanisms and health benefits. Nutrients 5: 1417 - 1435.

Steenbergen L, Sellaro R, van Hemert S, Bosch JA and Colzato LS. 2015. A randomized controlled trial to test the effect of multispecies probiotics on cognitive reactivity to sad mood. Brain Behav. Immun 48: 258 - 264.

Stefanescu C and Ciobica A. 2012. The relevance of oxidative stress status in first episode and recurrent depression. Journal of Affective Disorders 143: 34 38.

Taggart $\mathrm{H}$ and Bergstrom L. 2014. An Overview of the Microbiome and the Effects of Antibiotics. The Journal for Nurse Practitioners 10: 445 - 450.

Tillisch K, Labus J, Kilpatrick L, Jiang Z, Stains J, Ebrat B, Guyonnet D, LegrainRaspaud S, Trotin B, Naliboff B and Mayer EA. 2013. Consumption of fermented milk product with probiotic modulates brain activity. Gastroenterology 144: $1394-1401$.

Tillisch K. 2014. The effects of gut microbiota on CNS function in humans. Gut Microbes 5: $404-410$.

Turroni F, Ventura M, Buttó L F, Duranti S, Toole P WO, Motherway MO and Sinderen D. 2014. Molecular dialogue between the human gut microbiota and the host: a Lactobacillus and Bifidobacterium perspective. Cell. Mol. Life Sci. 71:183 - 203.

Valeur J, Puaschitz NG, Midtvedt T and Berstad A. 2016. Oatmeal porridge: impact on microflora-associated characteristics in healthy subjects. Br. J. Nutr. 115:62 - 67.

Zhang N, Huang X, Zeng Y, Wu X and Peng X. 2013. Study on prebiotic effectiveness of neutral garlic fructan in vitro. Food Science and Human Wellness 2: $119-123$.

\section{How to cite this article:}

Nasr, N.F. 2018. Psychological Impact of Probiotics and Fermented Foods on Mental Health of Human in Integrated Healthy Lifestyle. Int.J.Curr.Microbiol.App.Sci. 7(08): 2815-2822. doi: https://doi.org/10.20546/ijcmas.2018.708.296 